\title{
The chronic obstructive pulmonary disease assessment test improves the predictive value of previous exacerbations for poor outcomes in COPD
}

\author{
This article was published in the following Dove Press journal: \\ International Journal of COPD \\ 30 November 2015 \\ Number of times this article has been viewed
}

\author{
Marc Miravitlles' \\ Patricia García-Sidro² \\ Alonso Fernández-Nistal ${ }^{3}$ \\ María Jesús Buendía ${ }^{4}$ \\ María José Espinosa de \\ los Monteros ${ }^{5}$ \\ Cristina Esquinas' \\ Jesús Molina ${ }^{6}$ \\ 'Pneumology Department, Hospital \\ Universitari Vall d'Hebron, Ciber \\ de Enfermedades Respiratorias, \\ Barcelona, ${ }^{2}$ Pneumology Unit, \\ Hospital de la Plana, Villareal, ${ }^{3}$ Medical \\ Department, Takeda Farmacéutica \\ España S.A., Madrid, ${ }^{4}$ Pneumology \\ Department, Hospital Universitario \\ Infanta Leonor, Madrid, ${ }^{5}$ Pneumology \\ Department, Hospital Universitario \\ Virgen de la Salud, Toledo, ${ }^{6}$ Centro de \\ Salud "Francia", Fuenlabrada, Madrid, \\ Spain
}

Correspondence: Marc Miravitlles Pneumology Department, Hospital Universitari Vall d'Hebron,

Passeig Vall d'Hebron, I19-129, 08035 Barcelona, Spain

$\mathrm{Tel}+34932746083$

Fax +3493 2746083

Email mmiravitlles@vhebron.net

\begin{abstract}
Introduction: Chronic obstructive pulmonary disease (COPD) exacerbations have a negative impact on the quality of life of patients and the evolution of the disease. We have investigated the prognostic value of several health-related quality of life questionnaires to predict the appearance of a composite event (new ambulatory or emergency exacerbation, hospitalization, or death) over a 1-year follow-up.
\end{abstract}

Methods: This was a multicenter, prospective, observational study. Patients completed four questionnaires after recovering from an exacerbation (COPD Assessment Test [CAT], a Clinical COPD Questionnaire [CCQ], COPD Severity Score [COPDSS], and Airways Questionnaire [AQ20]). Patients were followed-up until the appearance of the composite event or for 1 year, whichever came first.

Results: A total of 497 patients were included in the study. The majority of them were men (89.7\%), with a mean age of 68.7 (SD 9.2) years, and a forced expiratory volume in 1 second of $47.1 \%$ (SD $17.5 \%$ ). A total of 303 (61\%) patients experienced a composite event. Patients with an event had worse mean scores of all questionnaires at baseline compared to patients without event: $\mathrm{CAT}=12.5$ vs $11.3(P=0.028) ; \mathrm{CCQ}=2.2$ vs $1.9(P=0.013)$; $\mathrm{COPDSS}=12.3$ vs $10.9(P=0.001) ; \mathrm{AQ} 20=8.3$ vs $7.5(P=0.048)$. In the multivariate analysis, only previous history of exacerbations and CAT score $\geq 13.5$ were significant risk factors for the composite event. A CAT score $\geq 13.5$ increased the predictive value of previous exacerbations with an area under the receiver operating characteristic curve of 0.864 (95\% CI: $0.829-0.899 ; P=0.001$ ).

Conclusion: The predictive value of previous exacerbations significantly increased only in one of the four trialled questionnaires, namely in the CAT questionnaire. However, previous history of exacerbations was the strongest predictor of the composite event.

Keywords: COPD, CAT, CCQ, COPDSS, AQ20, exacerbations

\section{Introduction}

At present, chronic obstructive pulmonary disease (COPD) is the fourth leading cause of death and estimates show that by 2030 COPD will become the third leading cause of death. ${ }^{1,2}$ Moreover, a recent study about the global burden of disease (measured in disability-adjusted life-years) places COPD in the second position. ${ }^{3}$

The chronic and progressive course of COPD is frequently aggravated by short periods of increased cough, dyspnea, and the production of sputum that can become purulent. ${ }^{1}$ These exacerbations have been shown to have a negative impact on healthrelated quality of life (HRQoL) and are the most frequent cause of medical visits, 
hospital admissions, and death among patients with COPD. ${ }^{4,5}$ From the aforementioned reasons, it is clear that there is a growing need to identify risk factors that can be used to identify the patients with high risk of exacerbations and mortality in order to take preventive decisions.

Among other factors, the association between HRQoL and the evolution of COPD (in terms of incidence of exacerbations, hospitalizations, and mortality) has been studied using specific individualized measurements of symptoms, such as dyspnea ${ }^{6}$ or cough and sputum ${ }^{7}$, or with standardized HRQoL questionnaires such as the St George's Respiratory Questionnaire., ${ }^{4,8}$ In general, these studies have found that increased symptoms and impaired HRQoL are associated with an increased risk of exacerbations and hospitalization. However, despite the good predictive ability of the St George's Respiratory Questionnaire, it is not always adaptable to routine clinical practice because of the long time required to be completed. Therefore, it would be very useful to have a short questionnaire with an adequate predictive value for poor outcomes in COPD.

The most widely used short questionnaires in COPD are the COPD Assessment Test (CAT), ${ }^{9}$ the Clinical COPD Questionnaire (CCQ), ${ }^{10}$ the Airways Questionnaire 20 (AQ20), ${ }^{11}$ and the COPD severity score (COPDSS). ${ }^{12}$ In particular, the CAT, AQ20, and CCQ have been tested for their predictive value for exacerbations and even mortality. ${ }^{13,14}$ However, there are no comparative studies using these questionnaires in the same population to investigate, which of them has the best predictive value for a series of poor outcomes in patients with moderate-to-severe COPD.

In this work, we assessed four HRQoL and severity questionnaires (CAT, CCQ, COPDSS, and AQ20) that can be used in daily clinical practice for their ability to predict one of the following new exacerbations, mortality, or hospitalization.

\section{Methods}

\section{Study design}

This was an observational, multicenter, prospective study aimed at evaluating the predictive value of different HRQoL and severity questionnaires in patients with COPD and with a high risk of experiencing exacerbations. The patients were recruited at presentation at the hospital or at primary care centers with symptoms of an exacerbation, and they were followed up for 1 year after recovery from the acute episode. We followed patients after recovery from an exacerbation, because these subjects are more likely to suffer a second episode during the follow-up. ${ }^{15}$
Those who met the inclusion and exclusion criteria were informed about the study and were asked to sign an informed consent form. The physicians in charge collected information at presentation or during the first 24 hours after admission. This information included demographic data, medical history, and comorbidities. The cardiovascular risk was assessed according to body mass index (BMI), sex, and waist circumference. ${ }^{16}$ Patients were asked to fill in CAT and CCQ questionnaires in their validated versions in Spanish. ${ }^{17,18}$

The patients were evaluated again after 4-6 weeks from the initial visit to assess clinical recovery. At this visit, patients filled out the CAT and CCQ again. Only those patients who recovered from the exacerbation were followed up for time to next exacerbation or death and comprise the population of this analysis. The characteristics of the included population and the course of the scores of the CAT and CCQ during recovery from the episode of exacerbation have been previously published. ${ }^{19}$

Patients who were considered recovered were administered the CCQ and AQ20 in addition to the CAT and CCQ, and these measurements were defined as a baseline. After this second visit, the patients were followed up for 1 year with two scheduled visits at 6 and 12 months, when all episodes of exacerbation were recorded.

\section{Ethics}

All participants in the study provided a written informed consent. The protocol was conducted in accordance with the principles of the Declaration of Helsinki, Guidelines for Good Clinical Practice, and in full conformity with regulations related to observational studies. The study was approved by the Research and Ethics Committee of the Hospital Clínic (Barcelona, Spain).

\section{Population}

Patients aged 40 years or above were recruited if they met the following inclusion criteria: 1) COPD demonstrated by spirometry performed in stable state not more than 12 months before recruitment, with a post-bronchodilator forced expiratory volume in 1 second $\left(\mathrm{FEV}_{1}\right) /$ forced vital capacity $<0.7$; 2) smoker or former smoker of at least 10 pack-years; and 3 ) experienced an exacerbation defined as an increase in respiratory symptoms that requires treatment with systemic corticosteroids, antibiotics or both, and/or hospitalization.

The exclusion criteria in the study were: 1) patients with another chronic respiratory disease; 2) patients with a COPD exacerbation due to other causes such as pneumonia, 
pneumothorax, and decompensated congestive heart failure; 3) patients requiring invasive or non-invasive mechanical ventilation; 4) patients who, in the opinion of the investigator, did not retain sufficient cognitive capacity, presenting sensory or psychiatric disability or language barriers that prevent or hinder a normal conduction of the study; and 5) patients participating in another study or clinical trial.

\section{Measurements}

The CAT consists of eight items with scores ranging from 0 to $5(0=$ no impairment, $5=$ greatest impairment $)$. An overall score is calculated by adding the score from each item with total scores ranging from 0 to 40 , higher scores indicating more severe health status impairment or a poorer control of COPD. ${ }^{9,20}$ The CCQ has three domains: symptoms (four items), functional status (four items), and mental state (two items $)$, graded on a 7-point Likert scale from 0 to $6(0=$ no impairment, $6=$ greatest impairment). ${ }^{10}$

The COPDSS is based on responses to survey items that comprise five overall aspects of COPD severity: respiratory symptoms (maximum 7 points), systemic corticosteroid use (maximum 5 points), other COPD medication use (maximum 10 points), previous hospitalization or intubation for respiratory disease ( 8 points), and home oxygen ( 5 points). Possible total scores range from 0 to 35 (higher scores reflect more severe COPD). ${ }^{12}$ The COPDSS has been translated and validated into Spanish. ${ }^{21}$

The AQ20 test consists of 20 items with "yes" responses scored as 1, and "no" and "not applicable" scored as 0 . The summary score ranges from 0 (best health) to 20 (worst health). ${ }^{22}$ The AQ20 has been translated and validated into Spanish. ${ }^{23}$

The cardiovascular risk was assessed according to BMI, sex, and waist circumference. ${ }^{16}$ The evaluation of waist circumference is used as a measure of the risks associated with overweight and obesity. It was not necessary to measure waist circumference in individuals with BMIs $\geq 35 \mathrm{~kg} / \mathrm{m}^{2}$ since it adds little to the predictive power of the disease risk classification of BMI. Waist circumference was measured to the nearest centimeter using a tape measure midway between the lower rib margin and the iliac crest. ${ }^{16}$

\section{Statistical analysis}

The primary objective of this study was to evaluate the predictive value of the CAT, CCQ, COPDSS, and AQ20 scores for the composite event. The event was defined as ambulatory exacerbation, emergency visit for an exacerbation, hospitalization by an exacerbation, or mortality during the 1-year follow-up.
In order to describe the qualitative variables, absolute frequencies and percentages were used. The description of quantitative variables was performed using the mean, standard deviation (SD), median, and quartiles. A comparison of qualitative variables between two or more groups was performed using the chi-square test and/or Fisher's exact test. A comparison of quantitative variables between two groups was performed using the Mann-Whitney $U$ test or Student's $t$-test, depending on the distribution of the data. The correlation between quantitative variables was performed using the Pearson correlation coefficient with a $95 \%$ confidence interval (CI).

To evaluate different quality of life questionnaires as predictors of the composite event, a binary variable was recorded. The best predictive cutoff point of each questionnaire score was obtained through receiver operating characteristic (ROC) curve analysis or from the median for those scores with less predictive value.

The Kaplan-Meier method was used to calculate survival graphics, and differences were assessed with the log-rank statistic. Four final models, one for each questionnaire were developed using a Back Stepwise Cox regression analysis including the composite event as dependent variable. Clinical relevant variables with a significance of $<0.2$ in the univariate analysis (age, sex, smoking status, $\mathrm{FEV}_{1}[\%]$, waist circumference, the number of exacerbations in the previous year, significant cardiovascular comorbidities) together with each questionnaire score were included as independent variables. The results have been described with hazard ratios with a $95 \% \mathrm{CI}$ and $P$-values.

We have made a ROC curve for the final model related to composite event and calculated the area under the curve (AUC) with its corresponding 95\% CI and their predictive value (sensitivity, specificity, positive predictive value, and negative predictive value). The statistical analysis was performed using the Statistical Package for the Social Sciences (SPSS) version 20.0 (SPSS Inc., Chicago, IL, USA).

\section{Results}

\section{Patient population}

A total of 675 exacerbated patients were recruited in the study. Of these, 498 (73.7\%) attended the second visit, fulfilled all inclusion criteria and were considered recovered from the exacerbation and $449(90.3 \%)$ completed the follow-up. These patients constitute the population of our study. Figure 1 shows the general outline of the study.

The demographic characteristics of the patients are shown in Table 1 . The majority were men $(89.7 \%)$, the mean age was 


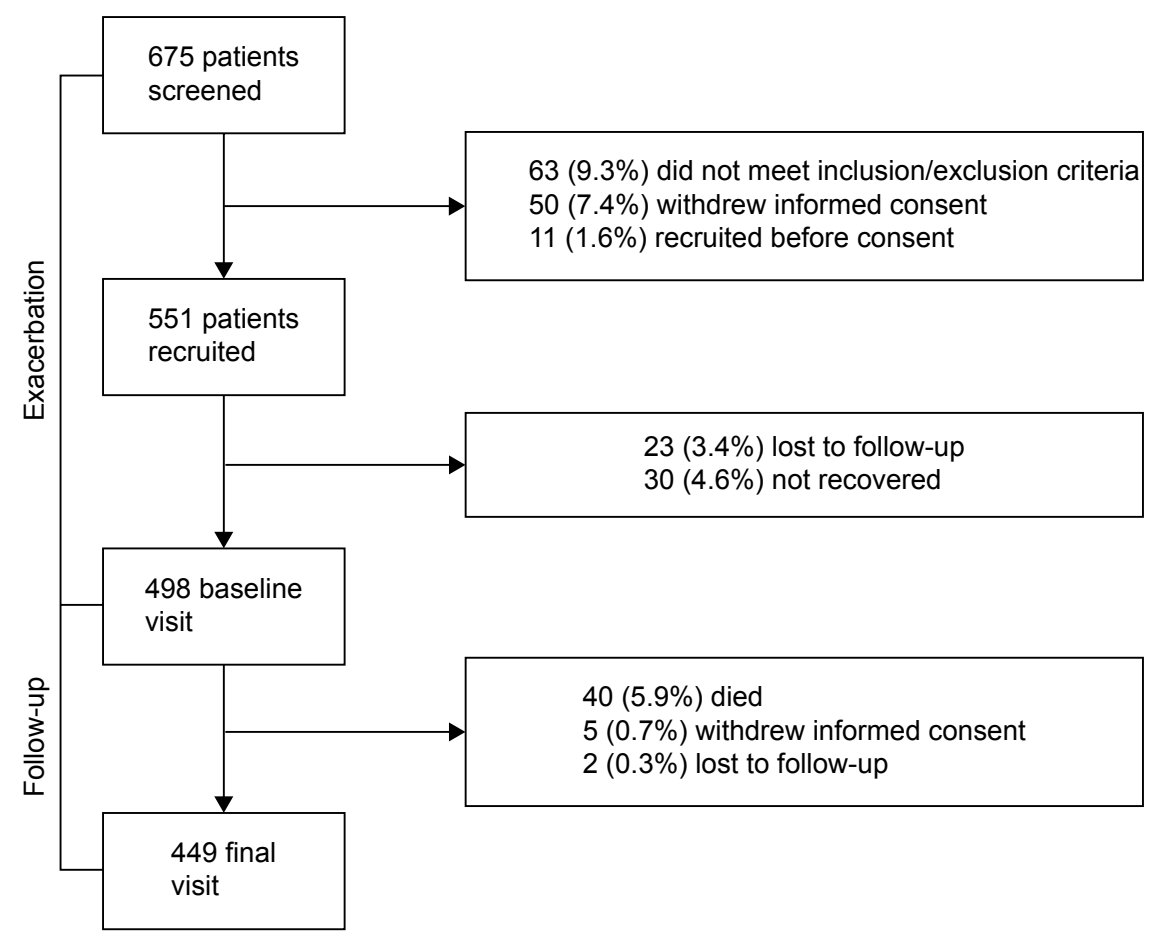

Figure I General outline of the study.

Table I Demographic, clinical characteristics and questionnaires' scores

\begin{tabular}{|c|c|c|c|c|}
\hline Variable & $\begin{array}{l}\text { Overall population } \\
(\mathrm{N}=497)\end{array}$ & $\begin{array}{l}\text { Composite event } \\
\text { (no) }(n=194)\end{array}$ & $\begin{array}{l}\text { Composite event } \\
\text { (yes) }(n=303)\end{array}$ & $P$-value \\
\hline Sex, male & $446(89.7 \%)$ & $17 \mid(88.1 \%)$ & $273(90.0 \%)$ & 0.970 \\
\hline Age (years) & $68.7(9.2)$ & $67.4(9.3)$ & $69.5(9.1)$ & 0.011 \\
\hline Body mass index $\left(\mathrm{kg} / \mathrm{m}^{2}\right)$ & $27.4(5.0)$ & $27.3(5.2)$ & $27.4(4.9)$ & 0.961 \\
\hline Active smokers & 147 (29.6\%) & $70(36.1 \%)$ & $77(25.4 \%)$ & 0.061 \\
\hline Smoking habits (packs-years) & $52.7(30.5)$ & $54.3(27.7)$ & $53.5(32.1)$ & 0.913 \\
\hline \multicolumn{5}{|l|}{ Cardiovascular risk } \\
\hline None & $133(26.7 \%)$ & $54(27.8 \%)$ & $79(26.1 \%)$ & 0.581 \\
\hline Increased & $127(25.5 \%)$ & $48(24.7 \%)$ & $79(26.1 \%)$ & \\
\hline High & $107(21.5 \%)$ & $36(18.6 \%)$ & $71(23.4 \%)$ & \\
\hline Very high & 124 (24.9\%) & $52(28.8 \%)$ & $72(23.7 \%)$ & \\
\hline Missing data & $6(0.01 \%)$ & $4(0.02 \%)$ & $2(0.01 \%)$ & \\
\hline Diabetes mellitus & $132(26.6 \%)$ & $63(32.4 \%)$ & $69(22.7 \%)$ & 0.117 \\
\hline Waist circumference $(\mathrm{cm})$ & $99.0(18.6)$ & $98.3(19.9)$ & $99.4(17.7)$ & 0.490 \\
\hline Time walking per day (minutes) & $62.8(88.0)$ & $65.2(80.4)$ & $61.1(92.8)$ & 0.621 \\
\hline Time of COPD evolution (years) & $10.2(8.5)$ & $9.7(9.5)$ & $10.6(7.7)$ & 0.282 \\
\hline Number of exacerbations in the previous year & $2.9(2.6)$ & $2.3(1.9)$ & $3.3(2.9)$ & $<0.001$ \\
\hline $\mathrm{FVC}(\mathrm{mL})$ & $2,245(1,050)$ & $2,416(1,064)$ & $2,136(1,028)$ & 0.004 \\
\hline FVC (\%) & $67.8(17.5)$ & $70.6(16.9)$ & $66.1(17.7)$ & 0.006 \\
\hline $\mathrm{FEV}_{1}(\mathrm{~mL})$ & $\mathrm{I},|\mathrm{I}| \mathrm{I}(624)$ & $1,282(662)$ & $\mathrm{I}, 052(583)$ & $<0.001$ \\
\hline $\mathrm{FEV}_{1}(\%)$ & $47.1(17.5)$ & $50.7(17.3)$ & $45.4(17.6)$ & 0.001 \\
\hline $\mathrm{FEV}_{1} / \mathrm{FVC}(\%)$ & $51.2(11.6)$ & $52.9(12.0)$ & $50.8(12.4)$ & 0.069 \\
\hline CAT (units) & $11.0(8.0-16.0)$ & $10.0(7.0-15.0)$ & II.0 (9.0-I5.0) & 0.028 \\
\hline CCQ (units) & $2.0(1.3-2.8)$ & $1.9(1.1-2.7)$ & $2.2(1.5-2.8)$ & 0.013 \\
\hline COPDSS (units) & $11.0(8.0-15.0)$ & $10.9(8.0-14.0)$ & $12.3(9.0-16.0)$ & 0.001 \\
\hline AQ20 (units) & $8.0(5.0-11.0)$ & $7.5(4.0-10.0)$ & $8.3(5.0-11.0)$ & 0.048 \\
\hline
\end{tabular}

Notes: Values are expressed as mean (SD) and frequency (\%). CAT, CCQ, COPDSS, and AQ20 questionnaires are expressed as median (interquartile range). P-value compares patients who suffered combined event with those who did not during the study follow-up.

Abbreviations: AQ20, Airways Questionnaire; CAT, COPD Assessment Test; CCQ, Clinical COPD Questionnaire; COPDSS, COPD Severity Score; FEV , forced expiratory volume in I second; FVC, forced vital capacity; SD, standard deviation. 
Table 2 Incidence of exacerbations, death and combined event during the I-year follow-up

\begin{tabular}{lll}
\hline & No of patients (\%) & Annual incidence (95\% Cl) \\
\hline Any severity of exacerbation & $295(59.4)$ & $1.008(0.899-1.126)$ \\
Ambulatory-treated exacerbations & $210(42.3)$ & $0.610(0.533-0.695)$ \\
Exacerbations requiring hospitalization & $124(24.9)$ & $0.309(0.259-0.366)$ \\
Exacerbations requiring emergency care & $107(21.5)$ & $0.259(0.214-0.310)$ \\
Mortality & $21(4.2)$ & $0.044(0.029-0.065)$ \\
Combined event & $303(6 I)$ & $1.035(0.925-1.155)$ \\
\hline
\end{tabular}

Abbreviations: $\mathrm{Cl}$, confidence interval; No, number.

$68.7(\mathrm{SD}=9.2)$ years, $147(29.6 \%)$ were active smokers and the mean $\mathrm{FEV}_{1}$ was $47.1 \%(\mathrm{SD}=17.5 \%)$. They had a mean of 2.9 $(\mathrm{SD}=2.6)$ moderate-to-severe exacerbations in the previous year. Table 1 shows the characteristics of the population as well as the scores of the questionnaires at baseline.

\section{Follow-up and characteristics of patients with composite event}

A composite event occurred in 303 (61\%) patients, with a median time from baseline to the event of 237 days (95\% CI: 195-276) and an annual incidence of 1.035 (95\% CI: 0.925-1.155) composite events per patient per year. A total of 295 (59.4\%) patients had some type of exacerbation. The incidences of each type of exacerbation are described in Table 2 .

The comparison of demographic, clinical, and functional characteristics as well as questionnaire scores between patients that suffered or not a composite event during the study follow-up is presented in Table 1. Patients who suffered from an event had a higher mean number of previous exacerbations at $3.3(\mathrm{SD}=2.9$ vs $2.3[\mathrm{SD}=1.9] ; P<0.001)$, more severely impaired lung function $\left(\mathrm{FEV}_{1} 45.4 \%[\mathrm{SD}=17.6 \%]\right.$ vs $50.7 \%$ $[\mathrm{SD}=17.3 \%] ; P=0.001)$ and worse scores in all questionnaires in comparison with patients without a composite event.

\section{Predictive value of the questionnaires for the composite event}

The first step was to investigate the best cutoff values of the different questionnaires for the composite event. For CAT and COPDSS, ROC curves indicate that the greatest predictive power was established at 13.5 and 9.5 points, respectively. Due to the poor predictive value of the ROC curves for CCQ and AQ20, the median values ( 2 and 8 points, respectively) were used to generate a binary variable. Using these cutoffs, all questionnaires, except the COPDSS, were significant predictors of the composite event in the univariate analysis (Table 3).

In the multivariate analysis, the Cox regression models constructed including the different questionnaires demonstrated that the number of exacerbations in the previous year was the only variable related to the composite event in all models. Among the questionnaires, only a CAT score $\geq 13.5$ points was associated with a significantly increased probability for a patient experiencing a composite event (hazard ratio: 1.396, 95\% CI: 1.076-1.812; Table 4 and Figure 2). This final model that included exacerbations in the previous year and a CAT score $\geq 13.5$ points had a high discriminatory power for the composite event (AUC $=0.864,95 \%$ CI: $0.829-0.899$; $P=0.001$; Figure 3 ), showing $92.5 \%$ sensitivity, $40.7 \%$ specificity, a $62 \%$ positive predictive value and $83.9 \%$ negative predictive value. This discriminatory power was higher than the one obtained by the history of previous exacerbations alone (AUC $=0.609,95 \%$ CI: 0.559-0.658; $P=0.001)$.

\section{Discussion}

The results of the current study have shown that patients that suffered a composite event (new moderate-to-severe exacerbation or death) during the 1-year follow-up after an exacerbation had significantly worse scores of HRQoL and severity questionnaires at baseline compared with patients that did not suffer an event. However, in the multivariate analysis, the number of previous exacerbations was the only predictor of the outcome in all models. Only the CAT scores $\geq 13.5$ remained significant in multivariate analysis and increased the predictive value of previous exacerbations for the composite event. In fact, CAT was the strongest predictor, and the predictive value of high CAT scores and

Table 3 Univariate analysis of predictive value of CAT, CCQ, COPDSS, and AQ20 scores for composite event according to the best identified cutoffs

\begin{tabular}{lllll}
\hline Variable & B & HR & $\mathbf{9 5 \% ~ C l}$ & P-value \\
\hline CAT $\geq 13.5$ & 0.357 & 1.430 & $1.115-1.833$ & 0.005 \\
CCQ $\geq 2$ & 0.310 & 1.364 & $1.063-1.749$ & 0.015 \\
COPDSS $\geq 9.5$ & 0.132 & 1.141 & $0.877-1.484$ & 0.32 \\
AQ20 $\geq 8$ & 0.270 & 1.310 & $1.020-1.683$ & 0.035 \\
\hline
\end{tabular}

Abbreviations: AQ20, Airways Questionnaire; B, beta coefficient; CAT, COPD Assessment Test; CCQ, Clinical COPD Questionnaire; $\mathrm{Cl}$, confidence interval; COPDSS, COPD Severity Score; HR, hazard ratio. 
Table 4 Predictive value of CAT, CCQ, COPDSS, and AQ20 scores for composite event, categorized into two categories as indicated

\begin{tabular}{|c|c|c|c|c|}
\hline Variable & B & HR & $95 \% \mathrm{Cl}$ & $P$-value \\
\hline \multicolumn{5}{|l|}{ CAT $(<\mid 3.5$ points and $\geq \mid 3.5$ points; $n=497)$} \\
\hline Age (years) & 0.015 & 1.015 & $0.999-1.031$ & 0.070 \\
\hline Smoking status (current vs former smoker RC) & -0.254 & 0.776 & $0.563-1.068$ & 0.119 \\
\hline $\mathrm{FEV}_{1}(\%)$ & -0.005 & 0.995 & $0.987-1.003$ & 0.200 \\
\hline Waist circumference & 0.001 & 1.001 & $0.994-1.008$ & 0.722 \\
\hline Number of exacerbations in the previous year & 0.056 & 1.058 & $1.018-1.100$ & 0.004 \\
\hline Significant cardiovascular comorbidity & -0.061 & 0.941 & $0.682-1.299$ & 0.712 \\
\hline CAT $\geq 13.5$ points & 0.334 & 1.396 & $1.076-1.812$ & 0.012 \\
\hline \multicolumn{5}{|l|}{ CCQ ( $<2$ points and $\geq 2$ points; $n=495$ ) } \\
\hline Age (years) & 0.015 & 1.015 & $0.999-1.03 \mid$ & 0.072 \\
\hline Smoking status (current vs former smoker RC) & -0.232 & 0.793 & $0.574-1.095$ & 0.159 \\
\hline $\mathrm{FEV}_{1}(\%)$ & -0.005 & 0.995 & $0.987-1.003$ & 0.210 \\
\hline Waist circumference & 0.000 & 1.000 & $0.993-1.003$ & 0.960 \\
\hline Number of exacerbations in the previous year & 0.055 & 1.056 & $1.015-1.099$ & 0.008 \\
\hline Significant cardiovascular comorbidity & -0.031 & 0.970 & $0.702-1.340$ & 0.852 \\
\hline $\mathrm{CCQ} \geq 2$ points & 0.167 & 1.182 & $0.902-1.549$ & 0.226 \\
\hline \multicolumn{5}{|l|}{ COPDSS ( $<9.5$ points and $\geq 9.5$ points; $n=497$ ) } \\
\hline Age (years) & 0.017 & 1.017 & $1.001-1.034$ & 0.042 \\
\hline Sex (male vs female RC) & 0.272 & 1.312 & $0.857-2.010$ & 0.212 \\
\hline Smoking status (current vs former smoker RC) & -0.245 & 0.782 & $0.569-1.076$ & 0.131 \\
\hline $\mathrm{FEV}_{1}(\%)$ & -0.008 & 0.992 & $0.984-1.001$ & 0.077 \\
\hline Number of exacerbations in the previous year & 0.068 & 1.070 & $1.030-1.113$ & 0.001 \\
\hline COPDSS $\geq 9.5$ points & -0.092 & 0.912 & $0.672-1.238$ & 0.555 \\
\hline \multicolumn{5}{|l|}{ AQ20 ( $<8$ points and $\geq 8$ points; $n=497)$} \\
\hline Age (years) & 0.013 & 1.014 & $0.998-1.029$ & 0.090 \\
\hline Smoking status (current vs former smoker RC) & -0.258 & 0.772 & $0.561-1.063$ & 0.113 \\
\hline $\mathrm{FEV}_{1}(\%)$ & -0.005 & 0.995 & $0.987-1.003$ & 0.198 \\
\hline Waist circumference & 0.000 & 1.000 & $0.993-1.007$ & 0.952 \\
\hline Number of exacerbations in the previous year & 0.058 & 1.060 & $1.019-1.102$ & 0.004 \\
\hline $\mathrm{AQ} 20 \geq 8$ points & 0.150 & 1.161 & $0.892-1.512$ & 0.267 \\
\hline
\end{tabular}

Notes: Independent variables: age, sex, smoking status, FEV (\%), waist circumference, number of exacerbations in the previous year, significant cardiovascular comorbidity, and $C A T \geq 13.5$ points. Dependent variable: combined event.

Abbreviations: AQ20, Airways Questionnaire; B, beta coefficient; CAT, COPD Assessment Test; CCQ, Clinical COPD Questionnaire; Cl, confidence interval; COPDSS, COPD Severity Score; $\mathrm{FEV}_{\text {, }}$, forced expiratory volume in I second; HR, hazard ratio; RC, reference category.

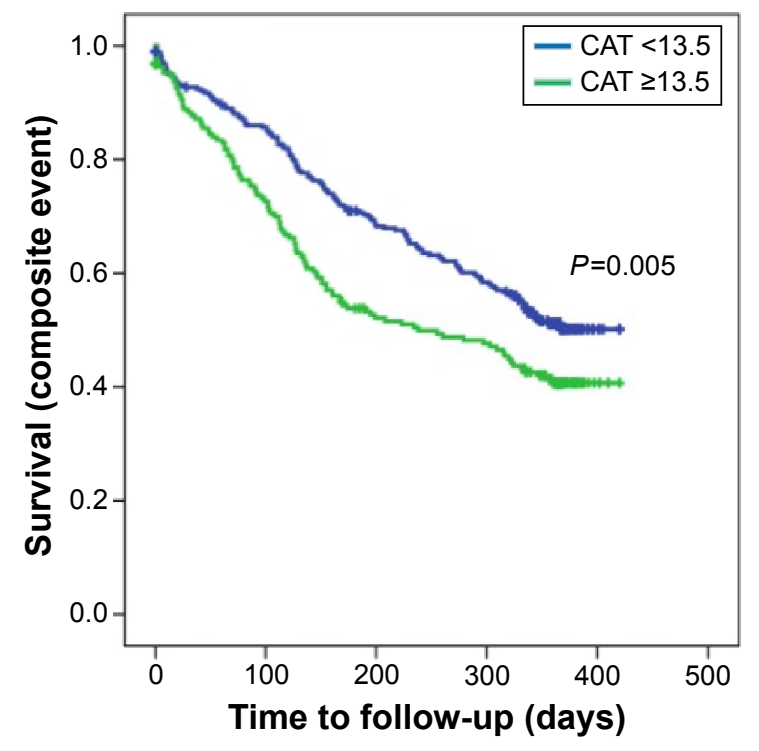

Figure 2 Kaplan-Meier curves comparing patients with CAT scores $\geq 13.5$ points with those with CAT scores $<13.5$ points for the composite event.

Abbreviation: CAT, COPD Assessment Test. frequent previous exacerbations for the composite event was high.

In the initial phase of the study, the CAT and CCQ scores were compared during an exacerbation of COPD. ${ }^{19}$ Scores were obtained during the first 24 hours after presentation at hospital or primary care centers with symptoms of an exacerbation, and 4-6 weeks later. We observed a significant improvement in scores of both questionnaires and a good correlation between their scores at onset of exacerbation and at recovery. ${ }^{19}$ The majority of exacerbated patients recovered and were included in the second phase of the study, which aimed at evaluating the predictive value of CAT, CCQ, COPDSS, and AQ20 for the occurrence of a composite event consisting of a new exacerbation (moderate-to-severe) or death during the 1-year follow-up.

In order to analyze the predictive value of the different questionnaires for the composite event, we enriched our 


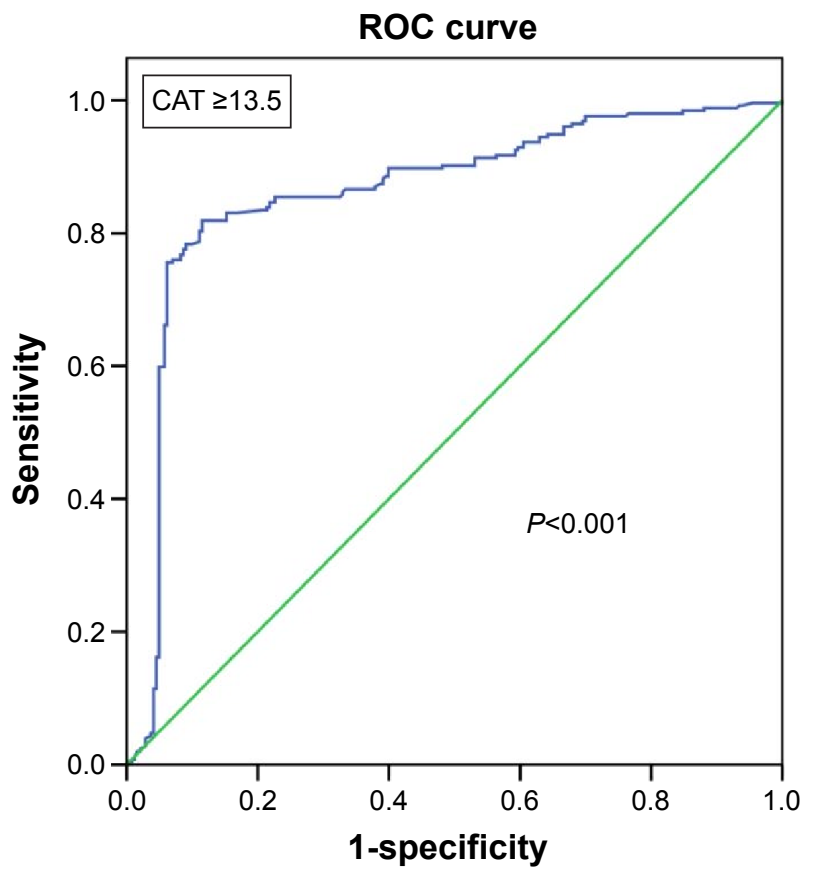

Figure 3 ROC analysis derived from the Cox regression model in its capacity to predict combined event. This model includes the number of exacerbations in the previous year and CAT $\geq 13.5$ points (AUC $=0.864, P<0.001$ ).

Abbreviations: ROC, receiver operating characteristic; CAT, COPD Assessment Test; AUC, area under the curve.

population with patients at increased risk of exacerbations. In fact, during the 1-year follow-up up to $61 \%$ of them presented with an event. Using the selected cutoff points, all questionnaires except the COPDSS were significant predictors of the composite event in the univariate analysis; however, only a CAT score $\geq 13.5$ persisted as a significant predictor of a poor outcome in the multivariate analysis, while the remaining questionnaires were no longer significant as predictors of risk.

The most relevant risk factor for the composite event was the history of previous exacerbations. The relevance of the history of previous exacerbations has been demonstrated in previous studies ${ }^{13,24}$ and supports the definition of a "frequent exacerbator" phenotype. ${ }^{25}$ Nevertheless, the demonstration of a CAT score $\geq 13.5$ in addition to the history of frequent exacerbations significantly increased the predictive value for combined event to reach an AUC of 0.864 .

Although the CAT has not been designed for use in exacerbations, the CAT scores can discriminate between stable and exacerbated COPD. The differences between both disease states range on average from 4 to 11 points. ${ }^{17,19,26-28}$ However, the use of the CAT to identify patients at risk of poor outcomes (exacerbation or death) has only recently been explored. Feliz-Rodriguez et al, ${ }^{29}$ in a group of 45 patients admitted for an exacerbation of COPD, observed that those who required a new hospitalization during the 3-month follow-up had higher scores during the first days of admission and higher AUC of CAT scores during the first 5 days of hospitalization. Lee et al ${ }^{13}$ categorized CAT scores in a population of stable COPD patients into four groups and observed that CAT scores showed strong prediction for time to first exacerbation, but in multivariate analysis, only the higher category (30-40 points) was significantly associated with increased risk of moderate-to-severe exacerbation compared with the lowest category (0-9 points). We have extended these results and found that after recovery from an exacerbation, those patients with a CAT score $\geq 13.5$ points are at significantly higher risk of relapse compared with patients with lower scores, independently of other risk factors.

Interestingly, the CCQ had predictive value only in univariate analysis, but it did not remain significant in multivariate analysis. In contrast, in our previous analysis of scores of questionnaires during the exacerbation, both CCQ and CAT provided similar information during recovery from exacerbations, and scores of both questionnaires showed an excellent correlation. ${ }^{19}$ Similarly, Antoniu et a ${ }^{30}$ demonstrated that CCQ was useful for the assessment of the dynamics of health status during hospitalization for exacerbations, and CCQ has also demonstrated to be useful in detecting exacerbations in COPD. ${ }^{31}$ Kocks et al ${ }^{32}$ observed that absence of improvement in CCQ symptom score was an independent predictor of treatment failure of an exacerbation of COPD. In contrast to our results, the same group showed that CCQ scores were significant predictors of time to re-exacerbation and 5-year mortality. ${ }^{33}$ It is of note that the analysis was performed dividing patients into tertiles of CCQ scores, while we aimed to identify a cutoff point of increased risk. These differences in the analysis could in part explain the different results. Similar to our results, Blanco-Aparicio et a ${ }^{14}$ found that CCQ was only a significant predictor of emergency visits in COPD during the 1-year follow-up, but was not a significant predictor of hospitalizations, and the predictive value for emergency visits disappeared during the 2-year follow-up.

The AQ20 is a brief HRQoL questionnaire for patients with asthma or COPD. In the aforementioned study, ${ }^{14}$ the authors demonstrated that AQ20 scores predicted emergency visits and hospitalizations in asthma, but not in COPD. This is consistent with our results that did not find a significant predictive value of AQ20 scores for the composite event in COPD.

Finally, we analyzed the predictive value of the COPDSS, which is not a HRQoL questionnaire, but a severity score. We previously demonstrated that COPDSS was a strong predictor of the risk of failure of treatment of an exacerbation of 
COPD,${ }^{33}$ and Eisner et $\mathrm{al}^{34}$ demonstrated that COPDSS scores were associated with the prospective risk of emergency visits and hospitalizations for exacerbation of COPD. Furthermore, a retrospective study in the USA using commercial claims data observed that COPDSS was an important predictor of 30-day unplanned readmission. ${ }^{35}$ However, we could not find a significant predictive value of COPDSS for the composite event in our population. A reason for this discrepancy could be at least in part the selection of our population, because exacerbation history and management have a high impact in COPDSS. Since all of our patients had a previous exacerbation, the COPDSS could not discriminate as well as if there were patients with and without previous exacerbations.

Mortality in our population was $4.2 \%$ at 1 year, which is almost identical at that observed in the large Toward a Revolution in COPD Health study at the end of the 1-year follow-up. ${ }^{36}$

Our study has some limitations. We have only included patients after recovery from an exacerbation; therefore, these results may not extrapolate to stable non-exacerbator COPD patients. The majority of our patients were males, which is in agreement with the epidemiological characteristics of COPD in Spain; ${ }^{37}$ therefore, the extrapolation of these results to women should be made with caution. For the objectives of the study, we tried to identify cutoffs regarding the scores, it is uncertain if the predictive value of the different questionnaires could be improved using different approaches such as analyzing scores by tertiles or quartiles. On the other hand, one of the strengths of our study is its observational design in a large sample of patients from primary and secondary care, which provides a high external validity.

\section{Conclusion}

Our results have shown that the previous history of exacerbations is the strongest predictor of the risk of experiencing the combined event after recovery from an exacerbation. The use of the CAT questionnaire significantly improves the predictive accuracy for the poor outcome, while other questionnaires were less reliable. These results should be confirmed in a large database of patients with different levels of risk of exacerbations.

\section{Acknowledgment}

This study has been funded by Takeda Farmacéutica España.

\section{Disclosure}

Marc Miravitlles has received speaker fees from Almirall, Boehringer Ingelheim, Pfizer, AstraZeneca, Chiesi, Esteve,
GlaxoSmithKline, Menarini, Grifols, and Novartis; and consulting fees from Almirall, Boehringer Ingelheim, Pfizer, GlaxoSmithKline, Gebro Pharma, CLS Behring, MediImmune, Takeda, Novartis, and Grifols. Alonso Fernández-Nistal is a full-time employee of Takeda Farmaceútica España. The other authors report no conflicts of interest in this work.

\section{References}

1. Decramer M, Janssens W, Miravitlles M. Chronic obstructive pulmonary disease. Lancet. 2012;379(9823):1341-1351.

2. Lozano R, Naghavi M, Foreman K, et al. Global and regional mortality from 235 causes of death for 20 age groups in 1990 and 2010: a systematic analysis for the Global Burden of Disease Study 2010. Lancet. 2012;380(9859):2095-2128.

3. Murray CJ, Lopez AD. Measuring the global burden of disease. NEngl J Med. 2013;369(5):448-457.

4. Seemungal TAR, Donaldson GC, Paul EA, Bestall JC, Jeffries DJ, Wedzicha JA. Effect of exacerbation on quality of life in patients with chronic obstructive pulmonary disease. Am J Respir Crit Care Med. 1998;157:1418-1422.

5. Escarrabill J, Torrente E, Esquinas C, et al. Clinical audit of patients hospitalized due to COPD exacerbation. MAG-1 study. Arch Bronconeumol. 2015;51:483-489.

6. Nishimura K, Izumi T, Tsukino M, Oga T. Dyspnea is a better predictor of 5-year survival than airway obstruction in patients with COPD. Chest. 2002;121(5):1434-1440.

7. Miravitlles M. Cough and sputum production as risk factors for poor outcomes in patients with COPD. Respir Med. 2011;105(8): $1118-1128$.

8. Doll H, Miravitlles M. Health-related QOL in acute exacerbations of chronic bronchitis and chronic obstructive pulmonary disease: a review of the literature. Pharmacoeconomics. 2005;23(4):345-363.

9. Jones PW, Harding G, Berry P, Wiklund I, Chen WH, Kline Leidy N. Development and first validation of the COPD Assessment Test. Eur Respir J. 2009;34(3):648-654.

10. van der Molen T, Willemse BW, Schokker S, ten Hacken NH, Postma DS, Juniper EF. Development, validity and responsiveness of the Clinical COPD Questionnaire. Health Qual Life Outcomes. 2003;1:13.

11. Hajiro T, Nishimura K, Jones PW, et al. A novel, short, and simple questionnaire to measure health-related quality of life in patients with chronic obstructive pulmonary disease. Am J Respir Crit Care Med. 1999; 159(6): 1874-1878.

12. Eisner MD, Trupin L, Katz PP, et al. Development and validation of a survey-based COPD severity score. Chest. 2005;127(6):1890-1897.

13. Lee SD, Huang MS, Kang J, et al. The COPD assessment test (CAT) assists prediction of COPD exacerbations in high-risk patients. Respir Med. 2014;108(4):600-608.

14. Blanco-Aparicio M, Vazquez I, Pita-Fernandez S, Pertega-Diaz S, Verea-Hernando H. Utility of brief questionnaires of health-related quality of life (Airways Questionnaire 20 and Clinical COPD Questionnaire) to predict exacerbations in patients with asthma and COPD. Health Qual Life Outcomes. 2013;11:85.

15. Hurst JR, Donaldson GC, Quint JK, Goldring JJ, Baghai-Ravary R, Wedzicha JA. Temporal clustering of exacerbations in chronic obstructive pulmonary disease. Am J Respir Crit Care Med. 2009;179(5): 369-374.

16. National Heart, Lung, and Blood Institute, National Institutes of Health. The Practical Guide: Identification, Evaluation, and Treatment of Overweight and Obesity in Adults. Available from: http://www. nhlbi.nih.gov/files/docs/guidelines/prctgd_c.pdf. Accessed October, 2000.

17. Agusti A, Soler JJ, Molina J, et al. Is the CAT questionnaire sensitive to changes in health status in patients with severe COPD exacerbations? COPD. 2012;9(5):492-498. 
18. Clinical COPD Questionnaire. Available from: http://www.ccq.nl/. Accessed December 11, 2013.

19. Miravitlles M, Garcia-Sidro P, Fernandez-Nistal A, Buendia MJ, Espinosa de los Monteros MJ, Molina J. Course of COPD assessment test (CAT) and clinical COPD questionnaire (CCQ) scores during recovery from exacerbations of chronic obstructive pulmonary disease. Health Qual Life Outcomes. 2013;11:147.

20. Soler-Cataluna JJ, Alcazar-Navarrete B, Miravitlles M. The concept of control of COPD in clinical practice. Int J Chron Obstruct Pulmon Dis. 2014;9:1397-1405.

21. Miravitlles M, Llor C, de Castellar R, Izquierdo I, Baro E, Donado E. Validation of the COPD severity score for use in primary care: the NEREA study. Eur Respir J. 2009;33(3):519-527.

22. Barley EA, Quirk FH, Jones PW. Asthma health status measurement in clinical practice: validity of a new short and simple instrument. Respir Med. 1998;92(10):1207-1214.

23. Blanco-Aparicio M, Vazquez-Rodriguez I, Verea-Hernando H. Cultural adaptation into Spanish of the Airways Questionnaire 20, a short health-related quality-of-life questionnaire for the clinical evaluation of asthma and chronic obstructive pulmonary disease. Arch Bronconeumol. 2009; 45(1):24-29.

24. Hurst JR, Vestbo J, Anzueto A, et al. Susceptibility to exacerbation in chronic obstructive pulmonary disease. $N$ Engl J Med. 2010;363(12): $1128-1138$.

25. Miravitlles M, Calle M, Soler-Cataluna JJ. Clinical phenotypes of COPD: identification, definition and implications for guidelines. Arch Bronconeumol. 2012;48(3):86-98.

26. Chang C, Zhu H, Shen N, et al. Bacterial infection, airway and systemic inflammation and clinical outcomes before and after treatment of AECOPD, a longitudinal and cross-sectional study. COPD. 2015;12(1): 19-30.

27. Pothirat C, Chaiwong W, Limsukon A, et al. Detection of acute deterioration in health status visit among COPD patients by monitoring COPD assessment test score. Int J Chron Obstruct Pulmon Dis. 2015; $10: 277-282$
28. Gupta N, Pinto LM, Morogan A, Bourbeau J. The COPD assessment test: a systematic review. Eur Respir J. 2014;44(4):873-884.

29. Feliz-Rodriguez D, Zudaire S, Carpio C, et al. Evolution of the COPD Assessment Test score during chronic obstructive pulmonary disease exacerbations: determinants and prognostic value. Can Respir J. 2013; 20(5):e92-e97.

30. Antoniu SA, Puiu A, Zaharia B, Azoicai D. Health status during hospitalisations for chronic obstructive pulmonary disease exacerbations: the validity of the Clinical COPD Questionnaire. Expert Rev Pharmacoecon Outcomes Res. 2014;14(2):283-287.

31. Trappenburg JC, Touwen I, de Weert-van Oene GH, et al. Detecting exacerbations using the Clinical COPD Questionnaire. Health Qual Life Outcomes. 2010;8:102.

32. Kocks JW, van den Berg JW, Kerstjens HA, et al. Day-to-day measurement of patient-reported outcomes in exacerbations of chronic obstructive pulmonary disease. Int J Chron Obstruct Pulmon Dis. 2013;8: 273-286.

33. Miravitlles M, Izquierdo I, Herrejon A, et al. COPD severity score as a predictor of failure in exacerbations of COPD. The ESFERA study. Respir Med. 2011;105(5):740-747.

34. Eisner MD, Omachi TA, Katz PP, Yelin EH, Iribarren C, Blanc PD. Measurement of COPD severity using a survey-based score: validation in a clinically and physiologically characterized cohort. Chest. 2010; 137(4):846-851.

35. Yu TC, Zhou H, Suh K, Arcona S. Assessing the importance of predictors in unplanned hospital readmissions for chronic obstructive pulmonary disease. Clinicoecon Outcomes Res. 2015;7:37-51.

36. Calverley PM, Anderson JA, Celli B, et al. Salmeterol and fluticasone propionate and survival in chronic obstructive pulmonary disease. N Engl J Med. 2007;356:775-789.

37. Miravitlles M, Soriano JB, Garcia-Rio F, et al. Prevalence of COPD in Spain: impact of undiagnosed COPD on quality of life and daily life activities. Thorax. 2009;64(10):863-868.
International Journal of COPD

\section{Publish your work in this journal}

The International Journal of COPD is an international, peer-reviewed journal of therapeutics and pharmacology focusing on concise rapid reporting of clinical studies and reviews in COPD. Special focus is given to the pathophysiological processes underlying the disease, intervention programs, patient focused education, and self management protocols.

\section{Dovepress}

This journal is indexed on PubMed Central, MedLine and CAS. The manuscript management system is completely online and includes a very quick and fair peer-review system, which is all easy to use. Visit http://www.dovepress.com/testimonials.php to read real quotes from published authors. 